\title{
Generation of representative primary virus isolates from blood plasma after isolation of HIV-1 with CD44 MicroBeads
}

\author{
Marion Cornelissen · Edwin J. Heeregrave • \\ Fokla Zorgdrager • Georgios Pollakis · \\ William A. Paxton • Antoinette C. van der Kuyl
}

Received: 21 May 2010/Accepted: 14 September 2010/Published online: 24 September 2010

(C) The Author(s) 2010. This article is published with open access at Springerlink.com

\begin{abstract}
Infection of cell cultures with cell-free virus isolated from HIV-infected patients is notoriously difficult and results in a loss of viral variation. Here, we describe viral sequences from PBMC, U87.CD4.CCR5 and U87.CD4.CXCR4 cell cultures and compare them to those from blood plasma from 12 patients from whom virus particles were isolated using CD44 MicroBeads. In both PBMC and U87.CD4.CCR5 cultures, 66\% of the plasma viral strains were retrieved after culturing. In addition, coreceptor use was predicted based on the env-V3 sequence and tested in U87.CD4 cells expressing either CCR5 or CXCR4. Recovery was lower for the CXCR4-using viruses. Only $50 \%$ of the virus clusters predicted to use CXCR4 could be retrieved from cell cultures, while $71 \%$ of CCR5using strains were found in U87.CCR5 cultures. Therefore, isolation of primary viruses with CD44 MicroBeads results in a good representation in cell culture of the in vivo divergence.
\end{abstract}

\section{Introduction}

For a virus that has established a worldwide epidemic, human immunodeficiency virus type 1 (HIV-1) virus particles have a surprisingly low infectivity in vitro. These low infectivity-to-particles ratios, ranging from $10^{-4}$ to $10^{-7}$ [1], are multifactorial. Factors include the time of

M. Cornelissen · E. J. Heeregrave · F. Zorgdrager ·

G. Pollakis - W. A. Paxton - A. C. van der Kuyl ( $\square)$

Laboratory of Experimental Virology, Department of Medical

Microbiology, Centre of Infection and Immunity Amsterdam

(CINIMA), Academic Medical Centre of the University

of Amsterdam, Meibergdreef 15, 1105 AZ Amsterdam,

The Netherlands

e-mail: a.c.vanderkuyl@amc.uva.nl absorption, the concentration of the virus, the target cell type and concentration, the diffusion coefficient and the half-life of the virus [2,3]. For the target cells used in the assays, both the radius and number of receptors available are factors of importance in retroviral infection. In addition, retrovirus preparations contain defective particles, although probably not as many as previously suggested [4]. Also, virus particles from patient samples can be bound by host proteins, e.g. complement factors, immunoglobulins or soluble CD4 (sCD4), which can influence infectiousness. Many of these aspects influencing infectivity are either inherent to the virus and cannot be changed or are at least difficult to manipulate. Because of the limitations of particle infectivity, isolation of replication-competent virus from HIV-infected patients is mainly done by coculture of patient PBMCs with donor cells $[5,6]$. This technique has the disadvantage that it can reactivate latent, archival strains that do not reflect the current replicating virus pool $[7,8]$, and it can severely reduce viral variation $[9,18]$. Therefore, optimization of virus particle infectiousness has been the target of many studies since the discovery of HIV, as there is a growing need to obtain primary isolates for neutralization assays, vaccine studies, determination of tropism, and drug testing. Varying the target cell or virus concentration has some effect on the infectivity of HIV-1 [1, 2], but more important enhancements have been achieved by increasing particle absorption to target cells through the addition of polybrene [7], by spinoculation [10], by Magnetofection [4], or with the help of CD44 MicroBeads [11]. These methods also work with serum or plasma virus from HIV-1-infected patients if viral copy numbers are adequate (generally $>100,000$ copies $\mathrm{vRNA} / \mathrm{ml})$.

An issue in HIV infections is the type of coreceptor molecule bound by the viral envelope proteins of the particle to enter cells. In most cases, this is either one of the 
chemokine receptors CCR5 or CXCR4. CCR5 is the most common coreceptor molecule, used by almost all primary HIV-1 strains. CXCR4 use, on the other hand, is an ability that arises later in infection and is associated with disease progression. Infecting U87.CD4 cells, a glioblastoma cell line engineered to express both the HIV CD4 receptor and an HIV coreceptor molecule, is the current method of choice when analysing HIV tropism. It is not known how much virus variation is regained when infecting U87.CD4 cells with primary isolates. Therefore, we have analysed the percentage recovery of the actual replicating virus population when using CD44 MicroBeads to isolate plasma virus and PBMCs or U87.CD4 cells expressing either CCR5 or CXCR4 to culture the primary strains of different HIV-1 subtypes. Virus particles were isolated from blood plasma of 12 HIV-1-infected patients. Viral clusters found in blood plasma, as determined by sequencing and phylogenetic analysis, were compared with the clusters found subsequently in the cell cultures so that the loss of variation experienced after in vitro infection could be estimated. In addition, coreceptor use of the different clusters was predicted genotypically and compared with the U87.CD4 cell culture outcome to determine if certain coreceptor-using virus variants were selectively lost.

\section{Materials and methods}

\section{Patient characteristics}

Twelve HIV-1-infected patients seen at the Academic Medical Centre (AMC) of the University of Amsterdam (Amsterdam, The Netherlands) were selected for this study based on their plasma viral load and HIV-1 subtype. Patient characteristics are summarized in Table 1. Blood plasma HIV-1 RNA levels were measured with the VERSANT HIV-1 RNA 3.0 assay (bDNA) (Bayer Diagnostics Division, Tarrytown, NY, USA). Plasma viral load ranged from 31,092 to $2,119,621$ copies/ml. HIV-1 subtypes included were subtype A $(4 \times)$, subtype $B(3 \times)$, subtype $D(1 \times)$, CRF01_AE $(1 \times)$, CRF02_AG $(2 \times)$ and CRF06_cpx $(1 \times)$. The current study showed that the patient infected with a subtype $\mathrm{D}$ strain, as indicated by direct sequence analysis of the pol gene in a genotyping assay, was actually infected with two HIV-1 strains: a subtype D and a subtype C strain.

Virus isolation

Blood plasma virus was isolated from $450 \mu$ l of plasma with the $\mu \mathrm{MACS}^{\mathrm{TM}}$ VitalVirus HIV Isolation Kit (Miltenyi Biotec B.V., Benelux) according to the manufacturer's instructions. Isolated virus was eluted in $200 \mu$ l.
Table 1 Patient and blood plasma virus characteristics

\begin{tabular}{|c|c|c|c|}
\hline $\begin{array}{l}\text { Patient } \\
\text { no. }(+/ \widehat{/})\end{array}$ & $\begin{array}{l}\text { Subtype (based } \\
\text { on the env gene) }\end{array}$ & $\mathrm{pVL}$ copies/ml & $\begin{array}{l}\text { CD4+ } \mathrm{T} \text { cell count } \\
\left(\times 10^{6} \text { cells } / \mathrm{ml}\right)\end{array}$ \\
\hline P99-01 శ̂ & CRF02_AG & 180,000 & $<50$ \\
\hline P03-01 శَ & CRF01_AE & 160,000 & 10 \\
\hline P04-01 శో & A & $1,300,000$ & 140 \\
\hline P07-01 శُ & CRF06_cpx & 434,536 & $<40$ \\
\hline $\mathrm{P} 07-02$ 우 & A1 & $2,119,621$ & 220 \\
\hline P07-03 శ̂ & A & 242,573 & 90 \\
\hline P07-04 우 & CRF02_AG & 212,595 & 70 \\
\hline P07-05 우 & B & 31,092 & 240 \\
\hline P07-06 우 & A & 605,399 & 120 \\
\hline P09-01 శَ & B & 138,205 & $670\left(\mathrm{PHI}^{\mathrm{a}}\right)$ \\
\hline P09-02 ๙ే & B & 527,746 & 300 \\
\hline P09-03 ㅇ & $C+D$ & 456,089 & 20 \\
\hline
\end{tabular}

${ }^{a}$ Primary HIV infection

Cell culture

U87.CD4 glioblastoma cells expressing either CCR5 or CXCR4 were used to determine coreceptor tropism of the blood plasma viruses isolated with the help of CD44 MicroBeads from 12 HIV-1 infected patients [12]. As a control, CD8+ T-cell-depleted interleukin-2 (Proleukin, Chiron, Emeryville, CA.) and phytohemagglutinin (bioTRADING Benelux, Mijdrecht, The Netherlands)-stimulated PBMC pooled from at least three uninfected donors were infected with the plasma virus isolates. CD8+ T cell depletion was done after 2 days using a Dynabeads M-450 CD8 kit (Invitrogen Corporation, Carlsbad, CA). PBMCs were cultured in RPMI 1640 medium (Invitrogen Corporation, Carlsbad, CA.) supplemented with $10 \%$ heat-inactivated foetal calf serum (FCS). U87 cells were cultured in DMEM (Invitrogen Corporation, Carlsbad, CA.), also supplemented with $10 \%$ heat-inactivated FCS. For the U87 cells, $2.5 \times 10^{5}$ cells were used per infection with $50 \mu$ isolated virus, while for the PBMCs, $2 \times 10^{5}$ cells were used per infection with $100 \mu \mathrm{l}$ of isolated virus. On days $2,6,9$ and 14 , culture supernatant was analysed with an in-house gag-p24 antigen capture enzyme-linked immunosorbent assay (ELISA) to monitor virus production. In addition, syncytia were scored using a microscope. Positive controls were infections of U87.CCR5 or U87.CXCR4 cells with the HIV-1 CCR5-using strains JR-FL (detection limit in U87.CCR5 cells: 10,000 copies vRNA), SF162 (detection limit in U87.CCR5 cells: 1,000 copies vRNA) and the CXCR4-using strain Lai (detection limit in U87.CXCR4 cells: 300 copies vRNA).

PCR amplification and sequence analysis

RNA was isolated from plasma samples and from cell cultures by a method using silica and guanidium thiocyanate 
[13]. A fragment of the HIV-1 env gene encompassing the V3 and V4 regions (nt 6950-7509 of the HXB2 reference sequence, GenBank Acc. No. K03455) was reverse transcribed, amplified, cloned using a TOPO TA Cloning Kit (Invitrogen, Carlsbad, CA.), and sequenced using a BigDye Terminator Cycle Sequencing Kit (Applied Biosystems, Foster City, CA.) as described [14]. Electrophoresis and data collection were performed on an ABI PRISM 3100 Genetic Analyser (also from Applied Biosystems). At least 15 clones were analysed for each sample.

Phylogenetic analysis and tropism prediction

The number of HIV-1 env sequence clusters present in each plasma sample was determined by phylogenetic analysis with the MEGA4 software package distributed by Sudhir Kumar, Arizona State University, Tempe (http://www.megasoftware.net). Distances were estimated by the Tamura-Nei method [15], using the gamma model to correct for multiple hits and to account for excess transitions, unequal nucleotide frequencies, and variation of the substitution rate among different sites. The shape parameter alpha, which describes the variation across sites by a gamma distribution, was set at 0.38 [16]. Phylogenetic trees were generated by the neighbour-joining method and bootstrap resampling with 1,000 replicates. The coreceptor use of a representative sequence of each cluster was predicted using both the $11 / 25$ rule and the Geno2pheno coreceptor option available at http://coreceptor.bioinf.mpiinf.mpg.de/index.php.

\section{Results}

U87.CD4 cell culture results

Virus was isolated with the aid of CD44 MicroBeads from 12 plasma samples with viral loads ranging from 31,092 to 2,119,621 copies/ml and harbouring different subtypes of HIV-1 group $M$ (Table 1). One hundred microliter of virus was used to infect $2 \times 10^{5}$ PBMCs as a positive control, and $50 \mu \mathrm{l}$ was used to infect either U87.CD4.CCR5 or U87.CD4.CXCR4 cells. Eleven out of twelve PBMC cultures became $\mathrm{p} 24$-antigen positive; one isolate did not grow in PBMC (Table 1). This isolate also did not grow in U87.CD4 cells, probably due to its low concentration $( \pm 30,000$ copies $/ \mathrm{ml})$. Ten out of twelve virus isolates replicated in U87.CD4.CCR5 cells (Table 1), while three U87.CD4.CXCR4 cultures were productively infected, as monitored both by $\mathrm{p} 24$ antigen production and syncytium formation. The virus isolates successfully growing in U87.CD4.CXCR4 cultures also scored positive in the accompanying U87.CD4.CCR5 culture, suggesting that the patients from whom they originated harboured both CCR5and CXCR4-using viruses, either as monotropic lineages or as dual-tropic viruses.

HIV-1 variation and coreceptor use

Viral lineages present in the patient's blood plasma were identified by phylogenetic analysis of env clones. The HIV-1 subtype was determined using the same env fragment, and this confirmed the original subtype classification based on the pol gene. For each cluster of sequences, coreceptor use was predicted in silico with both the geno2pheno [coreceptor] algorithm and the $11 / 25$ rule, which is based upon the presence of charged amino acids at positions 11 and 25 of the env-V3 loop (Table 2). To identify viral

Table 2 Geno/phenotype of plasma-derived HIV-1 isolated with CD44 beads

\begin{tabular}{|c|c|c|c|c|c|}
\hline $\begin{array}{l}\text { Patient } \\
\text { no. }\end{array}$ & $\begin{array}{l}\text { Env cluster } \\
\text { no. (plasma) }\end{array}$ & $\begin{array}{l}\text { Geno2pheno } \\
\text { prediction }\end{array}$ & $\begin{array}{l}11 / 25 \\
\text { rule }\end{array}$ & $\begin{array}{l}\text { PBMC } \\
\text { growth }\end{array}$ & $\begin{array}{l}\text { U87.R5 and/ } \\
\text { or U87.X4 }\end{array}$ \\
\hline \multirow[t]{2}{*}{ P99-01 } & 1 & R5 & R5 & + & R5 \\
\hline & 2 & R5 & R5 & - & R5 \\
\hline \multirow[t]{2}{*}{ P03-01 } & 1 & $\mathrm{X} 4$ & $\mathrm{R} 5$ & + & R5 \\
\hline & 2 & $\mathrm{X} 4$ & $\mathrm{X} 4$ & - & $\mathrm{X} 4$ \\
\hline \multirow[t]{3}{*}{ P04-01 } & 1 & $\mathrm{X} 4$ & $\mathrm{X} 4$ & + & $\mathrm{X} 4$ \\
\hline & 2 & R5 & R5 & + & R5 \\
\hline & 3 & $\mathrm{X} 4$ & $\mathrm{X} 4$ & + & $\mathrm{R} 5, \mathrm{X} 4$ \\
\hline \multirow[t]{2}{*}{ P07-01 } & 1 & $\mathrm{R} 5$ & $\mathrm{R} 5$ & - & $\mathrm{R} 5$ \\
\hline & 2 & R5 & $\mathrm{R} 5$ & - & R5 \\
\hline \multirow[t]{5}{*}{ P07-02 } & 1 & R5 & $\mathrm{X} 4$ & - & - \\
\hline & 2 & R5 & $\mathrm{R} 5$ & + & $\mathrm{R} 5$ \\
\hline & 3 & R5 & R5 & + & R5 \\
\hline & 4 & R5 & $\mathrm{R} 5$ & + & - \\
\hline & 5 & R5 & R5 & + & $\mathrm{R} 5$ \\
\hline \multirow[t]{3}{*}{ P07-03 } & 1 & R5 & R5 & - & $\mathrm{R} 5$ \\
\hline & 2 & R5 & R5 & - & - \\
\hline & 3 & R5 & $\mathrm{R} 5$ & + & $\mathrm{R} 5$ \\
\hline \multirow[t]{3}{*}{ P07-04 } & 1 & $\mathrm{X} 4$ & $\mathrm{X} 4$ & + & - \\
\hline & 2 & $\mathrm{X} 4$ & $\mathrm{X} 4$ & + & - \\
\hline & 3 & $\mathrm{R} 5$ & $\mathrm{R} 5$ & - & $\mathrm{R} 5$ \\
\hline P07-05 & ND & ND & ND & - & - \\
\hline \multirow[t]{2}{*}{ P07-06 } & 1 & R5 & $\mathrm{R} 5$ & - & - \\
\hline & 2 & R5 & $\mathrm{R} 5$ & + & - \\
\hline P09-01 & 1 & R5 & R5 & + & $\mathrm{R} 5$ \\
\hline \multirow[t]{3}{*}{ P09-02 } & 1 & R5 & $\mathrm{R} 5$ & + & - \\
\hline & 2 & R5 & $\mathrm{R} 5$ & + & - \\
\hline & 3 & $\mathrm{R} 5$ & $\mathrm{R} 5$ & + & $\mathrm{R} 5$ \\
\hline \multirow[t]{3}{*}{ P09-03 } & 1 & $\mathrm{X} 4$ & $\mathrm{X} 4$ & + & $\mathrm{X} 4$ \\
\hline & 2 & $\mathrm{X} 4$ & $\mathrm{X} 4$ & - & - \\
\hline & 3 & R5 & R5 & + & R5 \\
\hline
\end{tabular}

$N D$ Not determined 
strains capable of infecting specific cell cultures, viral RNA from each culture was also reverse-transcribed, PCR amplified, sequenced and analysed. Viral diversity in patients ranged from a virtually homogeneous population in a patient with an acute HIV infection (patient P09-01) to 5 separate virus clusters in a patient in the chronic phase of infection (patient P07-02) (Table 2). Most samples contained 2-3 distinct HIV-1 sequence clusters (Fig. 1). Genotypic prediction was usually in line with phenotypic outcome (Table 2). In four patients (P03-01, P04-01, P07-04, and P09-03), CXCR4 use was predicted for some clusters. For three of these patients, representative env-V3 sequences are shown in Fig. 2. In patient P03-01, one of the clusters predicted to use CXCR4 by the Geno2pheno algorithm but CCR5 by the $11 / 25$ rule was actually only found in the CCR5 culture. The other cluster, also predicted to use CXCR4, was indeed found in the U87.CXCR4 culture. In patient P04-01, one of the clusters predicted to be able to use CXCR4 was in fact a dual-tropic strain that was also found in the U87.CCR5 culture. For patient P07-04, CXCR4 use was predicted for two HIV-1 sequence clusters present in plasma, but repeated experiments did not show any growth in U87.CXCR4 cultures. However, infection of MT-2 cells, a cell line that only supports CXCR4-using HIV strains, produced gag-p24 after infection with virus isolated from patient $\mathrm{P} 07-04$ and formed syncytia, both of which are indicative of virus production [17]. This suggests that the MT-2 cell line is more sensitive to infection with CXCR4-using HIV than U87.CXCR4 cells are. Alternatively, the CXCR4 variants found in this patient could have further requirements for infection that go beyond coreceptor expression. Surprisingly, viruses isolated from patient P07-06 grew in PBMCs but not in U87.CD4 cell culture, suggesting a very low infectivity despite a plasma viral load $(\mathrm{pVL})$ of $>600,000$ copies $/ \mathrm{ml}$.

Overall, $71 \%$ of virus clusters predicted to use CCR5 as a coreceptor were indeed retrieved from U87.CCR5 cultures, but for CXCR4-using viruses, recovery was only around $50 \%$. This suggests that U87.CXCR4 cells are less sensitive to HIV infection or that CXCR4-using variants are minor variants in blood, resulting in a lower viral load, making them less efficient in in vitro infection. Also, some viruses could have been derived from early switchers that do not yet have the optimal ability to use CXCR4.

In patient P09-03, an unexpected dual infection with HIV-1 subtypes C and D was found, in which both subtypes were present in almost equal amounts in the plasma sample. Initial genotyping based upon a direct sequence from the pol gene suggested that this patient was infected with only a subtype D virus. Culturing of the plasma virus
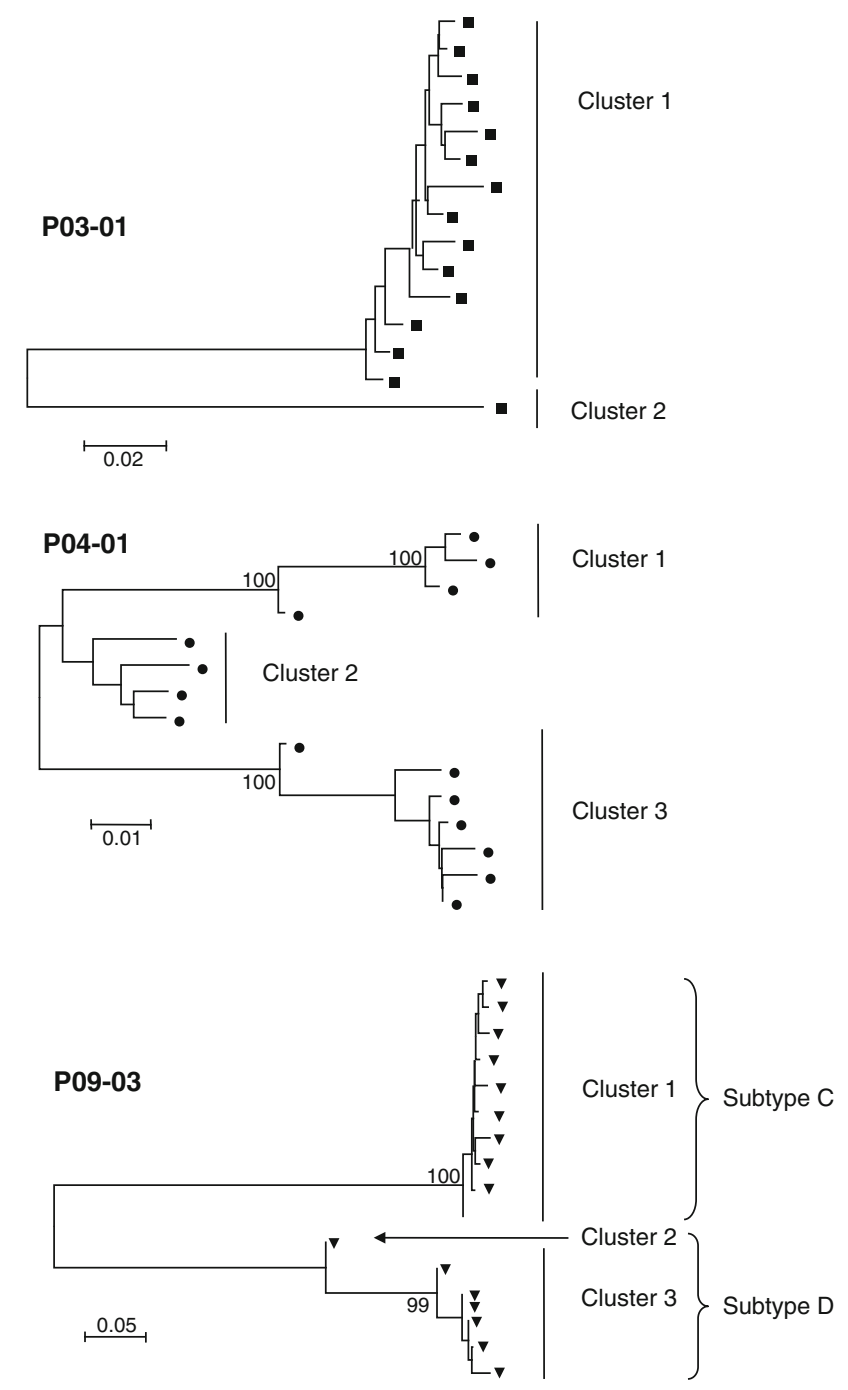

Fig. 1 Phylogenetic analysis of HIV env-V3 sequences. Neighbourjoining trees of blood plasma HIV-1 env-V3 sequences of three representative patients, P03-01 (CRF01_AE), P04-01 (subtype A), and P09-03 (subtypes C and D), are shown. Sequence clusters were identified using the trees and used for subsequent classification of sequences retrieved from cell cultures. The blood plasma minority sequence from patient P03-01, represented by a single sequence (labelled cluster 2), was faithfully retrieved from U87.CXCR4 cultures. The single sequence of patient P09-03, labelled cluster 2, was not retrieved from any cell culture. Genetic distances are indicated. Bootstrap values $\geq 90$ are shown

showed that subtype $\mathrm{C}$ was solely present in the U87.CCR5 cells, while subtype D sequences were exclusively found in the U87.CXCR4 cells. Both subtypes were found in the PBMC culture.

Besides the subtype D virus, CXCR4-using viruses in this study were a subtype A virus and the recombinant strain CRF01_AE. CRF02_AG variants from patient P07-04 were predicted to use CXCR4 but were not found in culture. All patients harbouring CXCR4-using viruses had CD4+ T cell counts $<150$ cells/ $\mu l$. 


\begin{tabular}{|c|c|c|c|c|c|c|}
\hline P03-01 & & $20 \quad 30$ & & & & \\
\hline Subtype & prediction & $\ldots|\ldots| \ldots|\ldots| \ldots|\ldots| \ldots|\ldots|$ & plasma & PBMC & $\mathrm{U} 87 . \mathrm{R} 5$ & U87.X4 \\
\hline CRF01_AE & $\mathrm{X} 4$ & CTKPNNNTRTRIRIGQRKMFYKT-EIVGTIKRAYC & 1 & & & 15 \\
\hline CRF01_AE & $\mathrm{X} 4$ or $\mathrm{R} 5$ * & ..R. ....KSTW . PGQV . RNGD.I.D.R. . . & 14 & 16 & 15 & \\
\hline P04-01 & & $\begin{array}{lll}10 & 20 & 30\end{array}$ & & & & \\
\hline Subtype & prediction & $\ldots|\ldots| \ldots|\ldots| \ldots|\ldots| \ldots|\ldots|$ & plasma & PBMC & $\mathrm{U} 87 . \mathrm{R} 5$ & U87. X4 \\
\hline A & $\mathrm{X} 4$ & CTRPNNYTRKSIYIGPGHSYHTKGKIIGDIRQAHC & 7 & 11 & & 5 \\
\hline A & $\mathrm{x} 4$ & 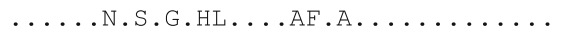 & 4 & 3 & 8 & 11 \\
\hline A & R5 & $\ldots \ldots$. . . . VHL ...KAFYAT.D....... & 4 & 2 & 7 & \\
\hline P09-03 & & 20 & & & & \\
\hline Subtype & prediction & $\ldots|\ldots| \ldots|\ldots| \ldots|\ldots| \ldots|\ldots|$ & plasma & PBMC & $\mathrm{U} 87 . \mathrm{R} 5$ & $\mathrm{U} 87 . \mathrm{X} 4$ \\
\hline $\mathrm{D}$ & $\mathrm{X} 4$ & CTRPYTYTKRITHMGSRRA-YFAEKITGNIRQAHC & 5 & 15 & & 15 \\
\hline $\mathrm{D}$ & $\mathrm{x} 4$ & $\ldots$.NN.R.G..PPG.-.T...D...Y. & 1 & & & \\
\hline $\mathrm{C}$ & R5 & .... NNN.RESIRI. PGQTI.ATGD.I.D. . . . . & 10 & 1 & 16 & \\
\hline
\end{tabular}

Fig. 2 Env-V3 sequences from patients P03-01, P04-01 and P09-03. The translated amino acid sequence of a representative env-V3 loop of the clusters found in plasma samples and subsequent cell cultures is shown for patients P03-01, P04-01, and P09-03. The number of clones belonging to the indicated env-V3 cluster recovered from blood plasma or cell cultures is shown. All three patients harboured CXCR4-using viruses. Coreceptor predictions by the Geno2pheno algorithm and the 11/25 rule, which generally agree, are indicated. ${ }^{*}$ Geno2pheno prediction $=\mathrm{X} 4 ; 11 / 25$ rule prediction $=\mathrm{R} 5$

the PBMC infection and $\pm 1,750$ particles each for the U87.CD4 cell cultures. However, the infectious viral load of this patient may be much lower. In an earlier study, the median ratio of infectious to total particles in patients with a plasma viral load between 10,000 and 100,000 copies/ml and a measurable infectious titre (79\% of patients in this pVL class) can be calculated to be around $1 / 4,700$ [7]. It is therefore likely that there are no or very few infectious particles in the isolates obtained from this patient's plasma.

Selection and lineage reduction are an important problem associated with cell culture $[9,18]$. A total of 29 different sequence clusters were detected in the plasma of 11 HIV-1-infected patients. Of these clusters, 19 (66\%) were retrieved from PBMC cultures, and another 19 were from U87.CD4 cell cultures, indicating that approximately $2 / 3$ of the variation present in plasma is recovered by culturing. For individual patients, culture outcome varied slightly. For three patients, an equal number of clusters were retrieved from both PBMC and U87 cultures. For four other patients, more clusters were obtained from PBMC culture than from U87 cultures. For the remaining four patients, the situation was reversed, with more clusters being retrieved from U87 cultures than from PBMCs. It is likely that sequencing more clones will result in the detection of additional clusters. Only in one patient with more than one sequence cluster, P04-01, were all plasma variants detected in the cell cultures. This patient had a very high $\mathrm{pVL}$ of 1,300,000 copies/ml and possessed not only CCR5- and CXCR4- using variants but also a dualtropic strain.

Isolation of HIV particles from blood plasma with the help of CD44 MicroBeads and subsequent infection of PBMCs or U87.CD4 cells resulted in an average retrieval of $50-66 \%$ of the virus clusters present in blood. Possibly, improvement could be achieved by infecting U87 cells $\mathrm{ml}$. This number translates into $\pm 3,500$ virus particles in 
with larger volumes of isolated virus, or by initially isolating virus from larger volumes of plasma. Although additional optimization is required, infecting U87.CD4 cells expressing either CCR5 or CXCR4 could be a new and convenient method for determination of tropism, since no amplification or cloning steps are required. However, plasma viral loads need to be substantial, in excess of 30,000 copies/ml.

Conflict of interest The authors declare that they have no conflict of interest.

Open Access This article is distributed under the terms of the Creative Commons Attribution Noncommercial License which permits any noncommercial use, distribution, and reproduction in any medium, provided the original author(s) and source are credited.

\section{References}

1. Layne SP, Merges MJ, Dembo M, Spouge JL, Conley SR, Moore JP, Raina JL, Renz H, Gelderblom HR, Nara PL (1992) Factors underlying spontaneous inactivation and susceptibility to neutralization of human immunodeficiency virus. Virology 189:695-714

2. Morgan JR, LeDoux JM, Snow RG, Tompkins RG, Yarmush ML (1995) Retrovirus infection: effect of time and target cell number. J Virol 69:6994-7000

3. Andreadis S, Lavery T, Davis HE, Le Doux JM, Yarmush ML, Morgan JR (2000) Toward a more accurate quantitation of the activity of recombinant retroviruses: alternatives to titre and multiplicity of infection. J Virol 74:3431-3439

4. Thomas JA, Ott DE, Gorelick RJ (2007) Efficiency of human immunodeficiency virus type 1 postentry infection processes: evidence against disproportionate numbers of defective virions. J Virol 81:4367-4370

5. Japour AJ, Fiscus SA, Arduino JM, Mayers DL, Reichelderfer PS, Kuritzkes DR (1994) Standardized microtiter assay for determination of syncytium-inducing phenotypes of clinical human immunodeficiency virus type 1 isolates. J Clin Microbiol 32:2291-2294

6. van 't Wout AB, Schuitemaker H, Kootstra NA (2008) Isolation and propagation of HIV-1 on peripheral blood mononuclear cells. Nat Protoc 3:363-370

7. Rusert P, Fischer M, Joos B, Leemann C, Kuster H, Flepp M, Bonhoeffer S, Gunthard HF, Trkola A (2004) Quantification of infectious HIV-1 plasma viral load using a boosted in vitro infection protocol. Virology 326:113-129

8. Verhofstede C, Vandekerckhove L, Eygen VV, Demecheleer E, Vandenbroucke I, Winters B, Plum J, Vogelaers D, Stuyver L (2009) CXCR4-using HIV type 1 variants are more commonly found in peripheral blood mononuclear cell DNA than in plasma RNA. J Acquir Immune Defic Syndr 50:126-136

9. Kusumi K, Conway B, Cunningham S, Berson A, Evans C, Iversen AK, Colvin D, Gallo MV, Coutre S, Shpaer EG (1992) Human immunodeficiency virus type 1 envelope gene structure and diversity in vivo and after cocultivation in vitro. $\mathrm{J}$ Virol 66:875-885

10. O'Doherty U, Swiggard WJ, Malim MH (2000) Human immunodeficiency virus type 1 spinoculation enhances infection through virus binding. J Virol 74:10074-10080

11. Whitcomb JM, Huang W, Fransen S, Limoli K, Toma J, Wrin T, Chappey C, Kiss LD, Paxinos EE, Petropoulos CJ (2007) Development and characterization of a novel single-cycle recombinant-virus assay to determine human immunodeficiency virus type 1 coreceptor tropism. Antimicrob Agents Chemother 51:566-575

12. Bjorndal A, Deng H, Jansson M, Fiore JR, Colognesi C, Karlsson A, Albert J, Scarlatti G, Littman DR, Fenyo EM (1997) Coreceptor usage of primary human immunodeficiency virus type 1 isolates varies according to biological phenotype. J Virol 71:7478-7487

13. Boom R, Sol CJ, Salimans MM, Jansen CL, Wertheim-van Dillen PM, van der Noordaa J (1990) Rapid and simple method for purification of nucleic acids. J Clin Microbiol 28:495-503

14. van der Kuyl AC, Zorgdrager F, Jurriaans S, Back NK, Prins JM, Brinkman K, van Eeden A, Bakker M, Cornelissen M (2009) Incidence of human immunodeficiency virus type 1 dual infections in Amsterdam, The Netherlands, during 2003-2007. Clin Infect Dis 48:973-978

15. Tamura K, Nei M (1993) Estimation of the number of nucleotide substitutions in the control region of mitochondrial DNA in humans and chimpanzees. Mol Biol Evol 10:512-526

16. Leitner T, Kumar S, Albert J (1997) Tempo and mode of nucleotide substitutions in gag and env gene fragments in human immunodeficiency virus type 1 populations with a known transmission history. J Virol 71:4761-4770

17. Koot M, Vos AH, Keet RP, de Goede RE, Dercksen MW, Terpstra FG, Coutinho RA, Miedema F, Tersmette M (1992) HIV-1 biological phenotype in long-term infected individuals evaluated with an MT-2 cocultivation assay. AIDS 6:49-54

18. Sabino E, Pan LZ, Cheng-Mayer C, Mayer A (1994) Comparison of in vivo plasma and peripheral blood mononuclear cell HIV-1 quasi-species to short-term tissue culture isolates: an analysis of tat and C2-V3 env regions. AIDS 8:901-909 